\title{
Recurrent Urothelial Carcinoma of the Renal Pelvis and Ureter
}

National Cancer Institute

\section{Source}

National Cancer Institute. Recurrent Urothelial Carcinoma of the Renal Pelvis and Ureter. NCl Thesaurus. Code C8254.

Reemergence of transitional cell carcinoma of the renal pelvis and ureter after a period of remission. 